\title{
Voltage Stability Bifurcation Analysis for AC/DC Systems with VSC-HVDC
}

\author{
Yanfang Wei, ${ }^{1}$ Zheng Zheng, ${ }^{1}$ Yonghui Sun, ${ }^{2}$ Zhinong Wei, ${ }^{2}$ and Guoqiang Sun ${ }^{2}$ \\ ${ }^{1}$ School of Electrical Engineering and Automation, Henan Polytechnic University, Jiaozuo 454000, China \\ ${ }^{2}$ College of Energy and Electrical Engineering, Hohai University, Nanjing 210098, China \\ Correspondence should be addressed to Yanfang Wei; weiyanfang@hpu.edu.cn
}

Received 24 January 2013; Accepted 1 March 2013

Academic Editor: Chuangxia Huang

Copyright (c) 2013 Yanfang Wei et al. This is an open access article distributed under the Creative Commons Attribution License, which permits unrestricted use, distribution, and reproduction in any medium, provided the original work is properly cited.

\begin{abstract}
A voltage stability bifurcation analysis approach for modeling AC/DC systems with VSC-HVDC is presented. The steady power model and control modes of VSC-HVDC are briefly presented firstly. Based on the steady model of VSC-HVDC, a new improved sequential iterative power flow algorithm is proposed. Then, by use of continuation power flow algorithm with the new sequential method, the voltage stability bifurcation of the system is discussed. The trace of the P-V curves and the computation of the saddle node bifurcation point of the system can be obtained. At last, the modified IEEE test systems are adopted to illustrate the effectiveness of the proposed method.
\end{abstract}

\section{Introduction}

As one of the key technologies of large scale access of distributed energy resources, the HVDC transmission system has great potential for further development $[1,2]$. Therefore, in the past decades, the problem associated with HVDC converters connected to weak AC networks has become an important research field. The one of particular interest, and highest in consequences, is the $\mathrm{AC}$ voltage stability at the HVDC terminals of the AC/DC systems [3, 4].

Voltage source converter-based HVDC (VSC-HVDC) is a new generation technology of HVDC, which overcomes some of the disadvantages of the traditional thyristor-based HVDC system, with a very broad application prospect. Compared to the conventional HVDC systems, the prominent features of the VSC-HVDC system are its potential to be connected to weak AC systems, independent control of active and reactive power exchange, and so on [4-6]. Due to those characteristics, many researches have been done for the exploitation of VSC-HVDC to enhance system stability of $\mathrm{AC} / \mathrm{DC}$ systems, that is, the improvement of transient stability $[7,8]$, the power oscillations damping $[9,10]$, the improvement of stability and power quality for wind farm based on VSC-HVDC grid-connected [11, 12], the stability analysis of multi-infeed DC systems with VSC-HVDC [13], and the keeping voltage stable [3, 14-17].

In $[14,15]$, the voltage stability analyses of AC/DC systems with VSC-HVDC were mainly based on simulation software, and the analysis based on power flow calculation was slightly inadequate. The power flow calculation of AC/DC systems is the premise and foundation of static security analysis, transient stability, voltage stability, small signal stability analysis, and so on [18-21]. At present, there are two main types of power flow algorithms for AC/DC systems, sequential iterative method $[21,22]$ and integrated iterative method $[23,24]$. The computational practice indicates that the convergence of integrated method is good, but the inheritance of the program is relatively poor, and the writing of program code needs huge work. The sequential iterative method has better program inheritance for pure AC program, but its convergence is not good. In view of these shortcomings, a modified sequential iterative power flow algorithm is proposed in this paper.

In [16], the continuation power flow (CPF) algorithm was presented to solve available transfer capability problem, but the saddle node bifurcation point was not discussed. In [17], the PV and QV curves were used to investigate voltage 


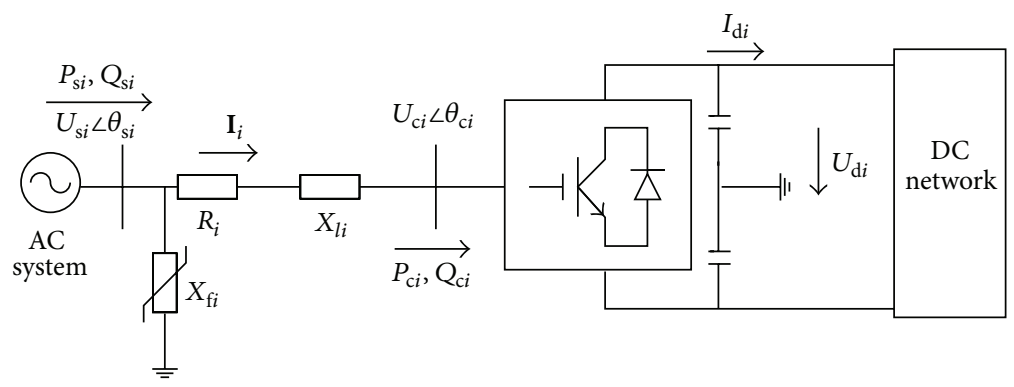

FIGURE 1: Simplified circuit diagram of single-phase VSC-HVDC.

stability of a weak two area AC network. Though many methods for voltage stability analysis of AC/DC systems with VSCHVDC have been proposed in different ways, few papers carefully consider the influence induced by different control modes of VSC-HVDC, which actually plays an important role on the voltage stability of the AC/DC systems. Motivated by the previous discussions, our main aim in this paper is to investigate the problem of power flow and voltage stability bifurcation for AC/DC systems with VSC-HVDC.

The rest of the paper is organized as follows. In Section 2, the steady model and control modes of AC/DC systems with VSC-HVDC are presented. In Section 3, the improved sequential iterative algorithm, the parameterization power flow and converter equations of VSC-HVDC, and the CPF strategy are presented. In Section 4, the model and method are applied to the modified IEEE 14- and IEEE 118-bus test systems with VSC-HVDC. Finally, in Section 5, the paper is completed with a conclusion.

\section{Steady Model of VSC-HVDC}

2.1. Power Flow Equations of VSC-HVDC. Figure 1 shows the single-line representation of two-terminal VSC-HVDC system. In Figure 1, $i$ is the number of VSC converters. $\mathbf{I}_{i}$ is the current flowing through transformer. $\mathbf{U}_{s i}=U_{s i} \angle \theta_{s i}$ is the AC side voltage vector of VSC converter. $\mathbf{U}_{\mathrm{c} i}=U_{\mathrm{c} i} \angle \theta_{\mathrm{c} i}$ is the output voltage vector of VSC converter. $R_{i}$ is the equivalent resistance of internal loss and converter transformer loss of VSC. $j X_{l i}$ is the impedance of converter transformer. $P_{s i}$ and $Q_{s i}$ are the power of AC system injected into converter transformer. $j X_{f}$ is the impedance of $A C$ filter. $\mathbf{I}_{\mathrm{d}}$ and $\mathbf{U}_{\mathrm{d}}$ are the DC current vector and DC voltage vector, respectively. $P_{\mathrm{c} i}$ and $Q_{\mathrm{c} i}$ are the power flowing through converter bridge. $P_{\mathrm{d} i}$ is the DC power. From Figure $1, \mathbf{I}_{i}$ can be expressed as follows:

$$
\mathbf{I}_{i}=\frac{\mathbf{U}_{\mathrm{s} i}-\mathbf{U}_{\mathrm{c} i}}{R_{i}+j X_{l i}} .
$$

The complex power $\widetilde{S_{s i}}$ of AC system is given by

$$
\widetilde{S_{s i}}=P_{s i}+j Q_{s i}=\mathbf{U}_{s i} \mathbf{I}_{i}^{*}
$$

To facilitate discussion, assume that $\delta_{i}=\theta_{\mathrm{si}}-\theta_{\mathrm{c} i},\left|Y_{i}\right|=$ $1 / \sqrt{R_{i}^{2}+X_{l i}^{2}}, \alpha_{i}=\operatorname{arccot}\left(X_{l i} / R_{i}\right)$, and substituting (1) into (2) yields

$$
\begin{gathered}
P_{s i}=-\left|Y_{i}\right| U_{s i} U_{c i} \cos \left(\delta_{i}+\alpha_{i}\right)+\left|Y_{i}\right| U_{s i}^{2} \cos \alpha_{i}, \\
Q_{s i}=-\left|Y_{i}\right| U_{s i} U_{c i} \sin \left(\delta_{i}+\alpha_{i}\right)+\left|Y_{i}\right| U_{s i}^{2} \sin \alpha_{i}+\frac{U_{s i}^{2}}{X_{\mathrm{f} i}} .
\end{gathered}
$$

Similarly, one has

$$
\begin{gathered}
P_{c i}=\left|Y_{i}\right| U_{s i} U_{c i} \cos \left(\delta_{i}-\alpha_{i}\right)-\left|Y_{i}\right| U_{c i}^{2} \cos \alpha_{i}, \\
Q_{c i}=-\left|Y_{i}\right| U_{s i} U_{c i} \sin \left(\delta_{i}-\alpha_{i}\right)-\left|Y_{i}\right| U_{c i}^{2} \sin \alpha_{i} .
\end{gathered}
$$

Since the loss of converter bridge-arm is equivalent by $R_{i}, P_{\mathrm{d} i}$ is qual to $P_{c i}$, and thus

$$
P_{\mathrm{d} i}=U_{\mathrm{d} i} I_{\mathrm{d} i}=\left|Y_{i}\right| U_{\mathrm{s} i} U_{\mathrm{c} i} \cos \left(\delta_{i}-\alpha_{i}\right)-\left|Y_{i}\right| U_{\mathrm{c} i}^{2} \cos \alpha_{i} .
$$

And $U_{c i}$ can be described as

$$
U_{\mathrm{c} i}=\frac{\sqrt{6} M_{i} U_{\mathrm{d} i}}{4}
$$

where $M(0<M<1)$ is defined as the PWM's amplitude modulation index.

The steady model of VSC-HVDC is given by (1)-(6) in the per-unit system (p.u.).

2.2. Steady-State Control Modes of VSC-HVDC. Several regular control modes for each VSC converter are chiefly as follows:

(1) constant DC voltage control, constant AC reactive power control;

(2) constant DC voltage control, constant AC voltage control;

(3) constant AC active power control, constant AC reactive power control;

(4) constant AC active power control, constant AC voltage control. 


\section{Voltage Stability Model for AC/DC Systems with VSC-HVDC}

3.1. The Modified Power Flow Algorithm Based on Sequential Iteration Method. For the previous model of AC/DC system with VSC-HVDC, the simplified power flow equations are given by

$$
\begin{gathered}
\mathbf{f}_{\mathrm{ac}}=0, \\
\mathbf{f}_{\mathrm{ac}-\mathrm{dc}}=0, \\
\mathbf{f}_{\mathrm{dc}}=0,
\end{gathered}
$$

where $\mathbf{f}_{\mathrm{ac}}=\left[\Delta P_{\mathrm{a} 1}, \Delta \mathrm{Q}_{\mathrm{a} 1}, \ldots, \Delta P_{\mathrm{a} n_{\mathrm{AC}}}, \Delta \mathrm{Q}_{\mathrm{an} n_{\mathrm{AC}}}\right]^{\mathrm{T}}, \mathbf{f}_{\mathrm{ac}-\mathrm{dc}}=\left[\Delta P_{\mathrm{t} 1}\right.$, $\left.\Delta Q_{\mathrm{t} 1}, \ldots, \Delta P_{\mathrm{t}_{\mathrm{vsc}}}, \Delta Q_{\mathrm{t} n_{\mathrm{vsC}}}\right]^{\mathrm{T}}, \mathbf{f}_{\mathrm{dc}}=\left[\Delta d_{11}, \Delta d_{12}, \Delta d_{13}, \Delta d_{14}\right.$, $\left.\ldots, \Delta d_{n_{\mathrm{VSC}} 1}, \Delta d_{n_{\mathrm{VSC} 2}}, \Delta d_{n_{\mathrm{VSC} 3}}, \Delta d_{n_{\mathrm{VSC}}}\right]^{\mathrm{T}}$.

To expand the Taylor series of (7), the second-order item and higher-order terms are omitted, and the modified equation based on Newton-Raphson is given by

$$
\mathbf{f}_{\mathrm{N}}=-\mathbf{J}_{\mathrm{N}} \Delta \mathbf{x}_{\mathrm{N}},
$$

where $\mathbf{f}_{\mathrm{N}}=\left[\mathbf{f}_{\mathrm{ac}}^{\mathrm{T}}, \mathbf{f}_{\mathrm{ac}-\mathrm{dc}}^{\mathrm{T}}, \mathbf{f}_{\mathrm{dc}}^{\mathrm{T}}\right]^{\mathrm{T}}, \Delta \mathbf{x}_{\mathrm{N}}=\left[\Delta x_{\mathrm{acl}}^{\mathrm{T}}, \Delta x_{\mathrm{ac} 2}^{\mathrm{T}}\right.$, $\left.\Delta x_{\mathrm{ac}-\mathrm{dc}}^{\mathrm{T}}, \Delta x_{\mathrm{dc}}^{\mathrm{T}}\right]^{\mathrm{T}}, \Delta \mathbf{x}_{\mathrm{ac} 1}=\left[\Delta U_{\mathrm{a} 1}, \Delta \theta_{\mathrm{a} 1}, \ldots, \Delta U_{\mathrm{an}}, \Delta \theta_{\mathrm{a} n_{\mathrm{AC}}}\right]^{\mathrm{T}}$, $\Delta \mathbf{x}_{\mathrm{ac} 2}=\left[\Delta U_{\mathrm{t} 1}, \Delta \theta_{\mathrm{t} 1}, \ldots, \Delta U_{\mathrm{t} n_{v S C}}, \Delta \theta_{\mathrm{t} n_{\mathrm{VSC}}}\right]^{\mathrm{T}}, \Delta \mathbf{x}_{\mathrm{ac}-\mathrm{dc}}=\left[\Delta P_{\mathrm{t} 1}\right.$, $\left.\Delta Q_{\mathrm{t} 1}, \ldots, \Delta P_{\mathrm{t}_{\mathrm{VSC}}}, \Delta Q_{\mathrm{t} n_{\mathrm{VSC}}}\right]^{\mathrm{T}}, \Delta \mathbf{x}_{\mathrm{dc}}=\left[\Delta U_{\mathrm{d} 1}, \Delta I_{\mathrm{d} 1}, \Delta \delta_{1}, \Delta M_{1}\right.$, $\left.\ldots, \Delta U_{\mathrm{d} n_{\mathrm{VSC}}}, \Delta I_{\mathrm{d} n_{\mathrm{VSC}}}, \Delta \delta_{n_{\mathrm{VSC}}}, \Delta M_{n_{\mathrm{VSC}}}\right]^{\mathrm{T}}$.

And $\mathbf{J}_{\mathrm{N}}$ is given by

$$
\begin{aligned}
& \mathbf{J}_{\mathrm{N}}\left(\mathbf{x}_{\mathrm{ac} 1}, \mathbf{x}_{\mathrm{ac} 2}, \mathbf{x}_{\mathrm{ac}-\mathrm{dc}}, \mathbf{x}_{\mathrm{dc}}\right) \\
&=\left[\begin{array}{cccc}
\frac{\partial \mathbf{f}_{\mathrm{ac}}}{\partial \mathbf{x}_{\mathrm{ac} 1}} & \frac{\partial \mathbf{f}_{\mathrm{ac}}}{\partial \mathbf{x}_{\mathrm{ac} 2}} & \frac{\partial \mathbf{f}_{\mathrm{ac}}}{\partial \mathbf{x}_{\mathrm{ac}-\mathrm{dc}}} & \frac{\partial \mathbf{f}_{\mathrm{ac}}}{\partial \mathbf{x}_{\mathrm{dc}}} \\
\frac{\partial \mathbf{f}_{\mathrm{ac}-\mathrm{dc}}}{\partial \mathbf{x}_{\mathrm{ac} 1}} & \frac{\partial \mathbf{f}_{\mathrm{ac}-\mathrm{dc}}}{\partial \mathbf{x}_{\mathrm{ac} 2}} & \frac{\partial \mathbf{f}_{\mathrm{ac}-\mathrm{dc}}}{\partial \mathbf{x}_{\mathrm{ac}-\mathrm{dc}}} & \frac{\partial \mathbf{f}_{\mathrm{ac}-\mathrm{dc}}}{\partial \mathbf{x}_{\mathrm{dc}}} \\
\frac{\partial \mathbf{f}_{\mathrm{dc}}}{\partial \mathbf{x}_{\mathrm{ac} 1}} & \frac{\partial \mathbf{f}_{\mathrm{dc}}}{\partial \mathbf{x}_{\mathrm{ac} 2}} & \frac{\partial \mathbf{f}_{\mathrm{dc}}}{\partial \mathbf{x}_{\mathrm{ac}-\mathrm{dc}}} & \frac{\partial \mathbf{f}_{\mathrm{dc}}}{\partial \mathbf{x}_{\mathrm{dc}}}
\end{array}\right] \\
&= {\left[\begin{array}{cccc}
\mathbf{J}_{\mathrm{a}-\mathrm{a} 1} & \mathbf{J}_{\mathrm{a}-\mathrm{a} 2} & \mathbf{0} & \mathbf{0} \\
\mathbf{J}_{\mathrm{ad}-\mathrm{a} 1} & \mathbf{J}_{\mathrm{ad}-\mathrm{a} 2} & \mathbf{J}_{\mathrm{ad}-\mathrm{ad}} & \mathbf{0} \\
\mathbf{J}_{\mathrm{d}-\mathrm{a} 1} & \mathbf{J}_{\mathrm{d}-\mathrm{a} 2} & \mathbf{J}_{\mathrm{d}-\mathrm{ad}} & \mathbf{J}_{\mathrm{d}-\mathrm{d}}
\end{array}\right] . }
\end{aligned}
$$

The power flow equation of VSC-HVDC is given as follows:

$$
\left[\begin{array}{l}
\mathbf{f}_{1} \\
\mathbf{f}_{2}
\end{array}\right]=-\left[\begin{array}{ll}
\mathbf{J}_{11} & \mathbf{J}_{12} \\
\mathbf{J}_{21} & \mathbf{J}_{22}
\end{array}\right]\left[\begin{array}{l}
\Delta \mathbf{x}_{1} \\
\Delta \mathbf{x}_{2}
\end{array}\right],
$$

where $\mathbf{f}_{1}=\mathbf{f}_{\mathrm{ac}}, \mathbf{f}_{2}=\left[\mathbf{f}_{\mathrm{ac}-\mathrm{dc}}^{\mathrm{T}}, \mathbf{f}_{\mathrm{dc}}^{\mathrm{T}}\right]^{\mathrm{T}}, \Delta \mathbf{x}_{1}=\Delta \mathbf{x}_{\mathrm{ac} 1}, \Delta \mathbf{x}_{2}=$ $\left[\Delta \mathbf{x}_{\mathrm{ac} 2}^{\mathrm{T}}, \Delta \mathbf{x}_{\mathrm{ac}-\mathrm{dc}}^{\mathrm{T}}, \Delta \mathbf{x}_{\mathrm{dc}}^{\mathrm{T}}\right]^{\mathrm{T}}, \mathbf{J}_{11}=\mathbf{J}_{\mathrm{a}-\mathrm{a} 1}, \mathbf{J}_{21}=\left[\begin{array}{c}\mathrm{J}_{\mathrm{ad}-\mathrm{al}} \\ \mathbf{J}_{\mathrm{d}-\mathrm{al}}\end{array}\right], \mathbf{J}_{12}=$ $\left[\mathbf{J}_{\mathrm{a}-\mathrm{a} 2}, \mathbf{0}, \mathbf{0}\right], \mathbf{J}_{22}=\left[\begin{array}{ccc}\mathbf{J}_{\mathrm{add}-\mathrm{a} 2} & \mathrm{~J}_{\mathrm{ad}-\mathrm{ad}} & \mathbf{0} \\ \mathbf{J}_{\mathrm{d}-\mathrm{a} 2} & \mathbf{J}_{\mathrm{d}-\mathrm{ad}} & \mathbf{J}_{\mathrm{d}-\mathrm{d}}\end{array}\right]$.

The number of the power flow equations for $(10)$ is $2(n-$ $1)+4 n_{\mathrm{VSC}}$, and the variables number is $2(n-1)+6 n_{\mathrm{VSC}}$. The $2 n_{\mathrm{VSC}}$ variables can be eliminated by control modes of VSC-HVDC. So, (10) has solutions. The dimensions of $\mathbf{f}_{1}$ are $2\left(n_{\mathrm{AC}}-1\right)$. The dimensions of $\Delta \mathbf{x}_{1}$ are $2\left(n_{\mathrm{AC}}-1\right)$. And the inverse matrix of $\mathbf{J}_{11}$ is exists. The dimensions of $\mathbf{f}_{2}$ are $6 n_{\mathrm{VSC}}$. The dimensions of $\Delta \mathbf{x}_{2}$ are $8 n_{\mathrm{VSC}}$, and the $2 n_{\mathrm{VSC}}$ dimensions of $\Delta \mathbf{x}_{2}$ can be eliminated by control modes of VSC-HVDC, and so the inverse matrix of $\mathbf{J}_{22}$ exists.

To expand (10),

$$
\begin{aligned}
& -\left(\mathbf{J}_{11} \Delta \mathbf{x}_{1}+\mathbf{J}_{12} \Delta \mathbf{x}_{2}\right)=\mathbf{f}_{1}, \\
& -\left(\mathbf{J}_{21} \Delta \mathbf{x}_{1}+\mathbf{J}_{22} \Delta \mathbf{x}_{2}\right)=\mathbf{f}_{2} .
\end{aligned}
$$
by

Then the new modified sequential iterative form is given

$$
\begin{aligned}
& \Delta \mathbf{x}_{1}=-\left[\mathbf{J}_{11}-\mathbf{J}_{12}\left(\mathbf{J}_{22}\right)^{-1} \mathbf{J}_{21}\right]^{-1}\left[\mathbf{f}_{1}-\mathbf{J}_{12}\left(\mathbf{J}_{22}\right)^{-1} \mathbf{f}_{2}\right], \\
& \Delta \mathbf{x}_{2}=-\left[\mathbf{J}_{22}-\mathbf{J}_{21}\left(\mathbf{J}_{11}\right)^{-1} \mathbf{J}_{12}\right]^{-1}\left[\mathbf{f}_{2}-\mathbf{J}_{21}\left(\mathbf{J}_{11}\right)^{-1} \mathbf{f}_{1}\right] .
\end{aligned}
$$

It can be seen from the previous derivation process that the modified algorithm does not make any hypothesis. The mutual influence between the AC system and DC system is fully considered in the iteration solution procedure. By means of the previous method, the problem of AC variables coupling DC variables is solved strictly in the mathematics expression. The matrix $\mathbf{J}_{11}$ and $\mathbf{J}_{12}$ can be obtained by the program of pure AC system.

3.2. Parameter-Dependent Power Flow and Converter Equations of VSC-HVDC. According to connected or not connected with a converter transformer, the buses of $\mathrm{AC} / \mathrm{DC}$ systems with VSC-HVDC are divided into two kinds, DC bus and pure AC bus [23]. The bus connected to primary side of a converter transformer is considered as a DC bus. The bus not connected to a converter transformer is considered as a pure AC bus. $n$ is the total bus number of the system. $n_{\mathrm{VSC}}$ is the number of VSC converters and also is the number of DC buses. So, the number of pure AC buses is $n_{\mathrm{AC}}=n-n_{\mathrm{VSC}}$.

Considering the load changes in several areas or a particular area (at a bus and/or at a group of buses) of the AC/DC systems with VSC-HVDC, the power flow equations for a pure $\mathrm{AC}$ bus are given by

$$
\begin{aligned}
\Delta P_{\mathrm{a} i}= & P_{\mathrm{a} i}-U_{\mathrm{a} i} \sum_{j \in i} U_{j}\left(G_{i j} \cos \theta_{i j}+B_{i j} \sin \theta_{i j}\right) \\
& +\left(P_{\mathrm{G} i}-P_{\mathrm{L} i}\right) \lambda=0, \\
\Delta Q_{\mathrm{a} i}= & Q_{\mathrm{a} i}-U_{\mathrm{a} i} \sum_{j \in i} U_{j}\left(G_{i j} \sin \theta_{i j}-B_{i j} \cos \theta_{i j}\right) \\
& +\left(Q_{\mathrm{G} i}-Q_{\mathrm{L} i}\right) \lambda=0,
\end{aligned}
$$

where the subscript "a" identifies that the bus is a pure AC bus, a $=1,2, \ldots, n_{\mathrm{AC}}$. The subscript " $i$ " is the number of the buses, $i=1,2, \ldots, n$. The subscript " $j$ " identifies that all the buses connected to the bus " $i$ " (expressed in the terms of $j \in i$ ). $U$ and $\theta$ are the bus voltage amplitude and phase angle, respectively. $G$ and $B$ are the real part and imaginary part of nodal admittance matrix, respectively. $P_{\mathrm{G} i}$ and $Q_{\mathrm{G} i}$ are the power of generator. $P_{\mathrm{L} i}$ and $Q_{\mathrm{L} i}$ are the loads at the bus $i$. $\lambda \in R$ are the parameters such real/reactive power demand at the buses and transmission line parameters. 
For a DC bus, the power flow equations are given by

$$
\begin{aligned}
\Delta P_{\mathrm{t} i}= & P_{\mathrm{t} i}-U_{\mathrm{t} i} \sum_{j \in i} U_{j}\left(G_{i j} \cos \theta_{i j}+B_{i j} \sin \theta_{i j}\right) \pm P_{\mathrm{t} i} \\
& +\left(P_{\mathrm{G} i}-P_{\mathrm{L} i}\right) \lambda=0, \\
\Delta Q_{\mathrm{t} i}= & Q_{\mathrm{t} i}-U_{\mathrm{t} i} \sum_{j \in i} U_{j}\left(G_{i j} \sin \theta_{i j}-B_{i j} \cos \theta_{i j}\right) \pm Q_{\mathrm{t} i} \\
& +\left(Q_{\mathrm{G} i}-Q_{\mathrm{L} i}\right) \lambda=0,
\end{aligned}
$$

where the subscript " $t$ " identifies the bus as a DC bus. " \pm " signs correspond to the rectifiers and inverters of VSCHVDC, respectively.

The basic power flow equations for VSC-HVDC converters are given as follows:

$$
\begin{aligned}
\Delta d_{k 1}= & P_{\mathrm{t} k}+\frac{\sqrt{6}}{4} M_{k} U_{\mathrm{t} k} U_{\mathrm{d} k}|Y| \cos \left(\delta_{k}+\alpha_{k}\right) \\
& -U_{\mathrm{t} k}^{2}|Y| \cos \alpha_{k}=0, \\
\Delta d_{k 2}= & Q_{\mathrm{t} k}+\frac{\sqrt{6}}{4} M_{k} U_{\mathrm{t} k} U_{\mathrm{d} k}|Y| \sin \left(\delta_{k}+\alpha_{k}\right)-U_{\mathrm{t} k}^{2}|Y| \sin \alpha_{k} \\
& -\frac{U_{\mathrm{t} k}^{2}}{X_{\mathrm{f} k}}=0, \\
\Delta d_{k 3}= & U_{\mathrm{t} k} I_{\mathrm{d} k}-\frac{\sqrt{6}}{4} M_{k} U_{\mathrm{t} k} U_{\mathrm{d} k}|Y| \cos \left(\delta_{k}-\alpha_{k}\right) \\
& +\frac{3}{8}\left(M_{k} U_{\mathrm{d} k}\right)^{2}|Y| \cos \alpha_{k}=0,
\end{aligned}
$$

where the subscript " $d$ " identifies that the variable as the DC side of VSC. " $k$ " is the $k$ th of VSC connected to DC network, $k=1,2, \ldots, n_{\mathrm{VSC}}$

For the $i$ th VSC converter, there are four unknown variables in (15); that is, $\mathbf{x}_{\mathrm{d} i}=\left[U_{\mathrm{d} i}, I_{\mathrm{d} i}, \delta_{i}, M_{i}\right]^{\mathrm{T}}$, and one more equation is needed to solve (15); that is,

$$
\mathbf{I}_{\mathrm{d}}=\mathbf{G}_{\mathrm{d}} \mathbf{U}_{\mathrm{d}} \text {, }
$$

where $\mathbf{G}_{\mathrm{d}}$ is the nodal admittance matrix of DC network.

Moreover, the DC network equation is given by

$$
\Delta d_{k 4}= \pm I_{\mathrm{d} k}-\sum_{s=1}^{n_{\mathrm{AC}}} g_{\mathrm{d} k s} U_{\mathrm{d} s}=0,
$$

where $g_{\mathrm{d} k}$ is the matrix element of nodal admittance matrix of DC network, $s=1,2, \ldots, n_{\mathrm{AC}}$.

In this paper, the concerned parameters are the real and reactive loads changes at the buses that can vary according to the following equations:

$$
\begin{aligned}
P_{i} & =P_{i 0}(1+\lambda), \\
Q_{i} & =Q_{i 0}(1+\lambda),
\end{aligned}
$$

where $P_{i 0}$ and $Q_{i 0}$ are the initial active and reactive loads, respectively. $P_{i}$ and $Q_{i}$ are the active and reactive loads at bus $i$, respectively.
For the previously AC/DC systems with VSC-HVDC, the simplified power flow equation with parameter $\lambda$-dependent is given by

$$
\mathbf{f}(\mathbf{x}, \lambda)=0 \text {, }
$$

where $\mathbf{f} \in R^{2(n-1)+4 n_{\mathrm{VSC}}+1}, \mathbf{x} \in R^{2(n-1)+4 n_{\mathrm{VSC}}+1} . \mathbf{f}$ is the balance equation of power flow. $\mathbf{x}$ is the system state variable such bus voltage magnitude and phase angles, DC system variables. $n_{1}$ and $n_{2}$ are the number of PQ and PV AC buses. The number of power flow equations for (19) is $2(n-1)+4 n_{\mathrm{VSC}}+1=$ $2 n_{1}+n_{2}+4 n_{\mathrm{VSC}}+1$.

\subsection{Continuation Power Flow Algorithm Based on Sequential} Iteration Method. CPF is a powerful tool to numerically generate $\mathrm{P}-\mathrm{V}$ curve to trace power system stationary behavior due to a set of power injection variations $[25,26]$. It uses predictor-corrector scheme to find a solution path of a set of power flow equations that have been reformulated to include a load parameter. $\left(x_{l}, \lambda_{l}\right)^{\mathrm{T}}$ is the initial state of the power flow solution curve, where the subscript " $l$ " is the iteration number of predictor-corrector scheme based on NewtonRaphson algorithm in CPF.

3.3.1. The Predictor Step. The predictor step is a stage in firstorder differential form. Once a base solution has been found $(\lambda=0)$, a prediction of the next solution can be made by taking an appropriately sized step in a direction tangent to the solution path. Taking the derivatives of (19) will result in the following total differential form equation:

$$
\left[\begin{array}{ll}
f_{x}^{\prime} & f_{\lambda}^{\prime}
\end{array}\right]\left[\begin{array}{l}
d_{x} \\
d_{\lambda}
\end{array}\right]=0
$$

where $f_{x}^{\prime}=\partial f / \partial x$ is the Jacobian matrix of power flow equation with $x . f_{\lambda}^{\prime}=\partial f / \partial \lambda$ is the partial derivative of power flow equation with $\lambda .\left[d_{x} d_{\lambda}\right]^{\mathrm{T}}$ is the tangent vector, which is the computation target of the predictor step.

Since the insertion of $\lambda$ in the power flow equation added an unknown variable, one more equation is needed to solve the previously equation. This is satisfied by setting one of the components of the tangent vector to +1 or -1 . This component is referred to as the continuation parameter. Equation (20) now becomes [23]

$$
\left[\begin{array}{ll}
f_{x}^{\prime} & f_{\lambda}^{\prime} \\
e_{K} &
\end{array}\right]\left[\begin{array}{l}
d_{x} \\
d_{\lambda}
\end{array}\right]=\left[\begin{array}{c}
0 \\
\pm 1
\end{array}\right],
$$

where $e_{K}$ is a row vector with all elements equal to zero except for the $K$ th element being equal 1 . The dimensions of $e_{K}$ are $1 \times\left[2(n-1)+6 n_{\mathrm{VSC}}+1\right]$. The introduction of the additional equation makes the Jacobian matrix nonsingular at the critical operation point. The modified equation of Newton-Raphson algorithm for (21) is

$$
\Delta \mathbf{f}=-\mathbf{J} \Delta \mathbf{x},
$$

where $\Delta \mathbf{f}=\left[\mathbf{f}_{\mathrm{ac}}^{\mathrm{T}}, \mathbf{f}_{\mathrm{ac}-\mathrm{dc}}^{\mathrm{T}}, \mathbf{f}_{\mathrm{dc}}^{\mathrm{T}}, \mathbf{f}_{\lambda}^{\mathrm{T}}\right]^{\mathrm{T}}, \mathbf{f}_{\lambda}= \pm 1, \Delta \mathbf{x}=\left[\Delta x_{\mathrm{ac} 1}^{\mathrm{T}}, \Delta x_{\mathrm{ac} 2}^{\mathrm{T}}\right.$, $\left.\Delta x_{\mathrm{ac}-\mathrm{dc}}^{\mathrm{T}}, \Delta x_{\mathrm{dc}}^{\mathrm{T}}, \Delta x_{\lambda}^{\mathrm{T}}\right]^{\mathrm{T}}, \mathrm{J}$ is referred to as the Jocobian matrix 
TABLE 1: System parameters of operation and control modes of VSC-HVDC.

\begin{tabular}{|c|c|c|}
\hline \multirow{2}{*}{ Operation modes } & \multicolumn{2}{|c|}{ Control parameters of VSC converters (p.u.) } \\
\hline & $\mathrm{VSC}_{1}$ & $\mathrm{VSC}_{2}$ \\
\hline \multirow{2}{*}{1} & Constant DC voltage $U_{\mathrm{d} 1}^{\mathrm{ref}}=2.0000$ & Constant AC active power $P_{\mathrm{s} 2}^{\mathrm{ref}}=-0.8993$ \\
\hline & Constant $\mathrm{AC}$ reactive power $Q_{\mathrm{sl}}^{\mathrm{ref}}=0.1220$ & Constant $\mathrm{AC}$ reactive power $Q_{\mathrm{s} 2}^{\mathrm{ref}}=0.1734$ \\
\hline \multirow{2}{*}{2} & Constant DC voltage $U_{\mathrm{d} 1}^{\text {ref }}=2.0000$ & Constant AC active power $P_{\mathrm{s} 2}^{\mathrm{ref}}=-0.8993$ \\
\hline & Constant $\mathrm{AC}$ reactive power $Q_{\mathrm{sl}}^{\mathrm{ref}}=0.1220$ & Constant AC voltage $U_{\mathrm{s} 2}^{\mathrm{ref}}=1.0186$ \\
\hline \multirow{2}{*}{3} & Constant DC voltage $U_{\mathrm{d} 2}^{\text {ref }}=1.9863$ & Constant AC active power $P_{\mathrm{s} 1}^{\text {ref }}=0.9194$ \\
\hline & Constant AC voltage $U_{s 2}^{\text {ref }}=1.0186$ & Constant $\mathrm{AC}$ reactive power $Q_{\mathrm{s} 1}^{\mathrm{ref}}=0.1220$ \\
\hline \multirow{2}{*}{4} & Constant DC voltage $U_{\mathrm{d} 2}^{\mathrm{ref}}=1.9863$ & Constant AC active power $P_{\mathrm{s} 1}^{\mathrm{ref}}=0.9194$ \\
\hline & Constant AC voltage $U_{s 2}^{\mathrm{ref}}=1.0186$ & Constant AC voltage $U_{s 1}^{\text {ref }}=1.0203$ \\
\hline
\end{tabular}

TABLE 2: Initial DC variable parameters (p.u.) of VSC-HVDC system.

\begin{tabular}{lcccccccccc}
\hline$N_{\text {bus }}$ & $R$ & $X_{1}$ & $P_{\mathrm{L}}$ & $Q_{\mathrm{L}}$ & $R_{\mathrm{d}}$ & $U_{\mathrm{s}}$ & $\theta_{\mathrm{s}}$ & $P_{\mathrm{s}}$ & $Q_{\mathrm{s}}$ & $U_{\mathrm{d}}$ \\
\hline 13 & 0.0060 & 0.1500 & 0.1350 & 0.0580 & 0.0300 & 1.0000 & 0.0000 & 0.9190 & 0.1220 & 2.0000 \\
14 & 0.0060 & 0.1500 & 0.1490 & 0.0500 & 0.0300 & 1.0000 & 0.0000 & -0.8990 & 0.1730 & 2.0000 \\
\hline
\end{tabular}

of (22), and the dimensions of $\mathbf{J}$ are $\left[2(n-1)+4 n_{\mathrm{VSC}}+1\right] \times$ $\left[2(n-1)+6 n_{\mathrm{VSC}}+1\right]$.

The initial values of the variables of VSC-HVDC system for power flow program iteration are given by

$$
\begin{gathered}
U_{\mathrm{d} k}^{(0)}=U_{\mathrm{d} k}^{\mathrm{ref}}, \quad(k \in C V), \\
U_{\mathrm{d} k}^{(0)}=U_{\mathrm{d} k}^{\mathrm{N}}, \quad(k \notin C V), \\
I_{\mathrm{d} k}^{(0)}=\frac{P_{\mathrm{t} k}}{U_{\mathrm{d} k}^{(0)}}, \\
\delta_{k}^{(0)}=\arctan \left(\frac{P_{\mathrm{t} k}}{\left(U_{\mathrm{t} k}^{2} / X_{\mathrm{L} k}\right)+\left(U_{\mathrm{t} k}^{2} / X_{\mathrm{f} k}\right)-Q_{\mathrm{t} k}}\right), \\
M_{k}^{(0)}=\frac{2 \sqrt{6}}{3} \frac{P_{\mathrm{t} k} X_{\mathrm{L} k}}{U_{\mathrm{t} k} U_{\mathrm{d} k}^{(0)} \sin \delta_{k}^{(0)}},
\end{gathered}
$$

where $k \in C V$ identifies that the $k$ th VSC is constant DC voltage control mode. $k \notin C V$ identifies that the $k$ th is not constant DC voltage control mode. Superscript "0" identifies the initial value of the 0th iteration. Superscript "ref" identifies that the variable value is reference value. Superscript "N" identifies rated value.

The $P_{\mathrm{t} k}$ is given in estimation by

$$
P_{\mathrm{t} k}=-\sum_{s=1, s \notin C V}^{n_{\mathrm{VSC}}} P_{\mathrm{t} s}^{\mathrm{ref}}
$$

Based on the previous analysis, the tangent vector $\left[\begin{array}{ll}d_{x} & d_{\lambda}\end{array}\right]^{\mathrm{T}}$ is obtained. The prediction value of the next solution is given by

$$
\left[\begin{array}{l}
x_{l+1}^{\prime} \\
\lambda_{l+1}^{\prime}
\end{array}\right]=\left[\begin{array}{l}
x_{l} \\
\lambda_{l}
\end{array}\right]+h\left[\begin{array}{l}
d_{x} \\
d_{\lambda}
\end{array}\right]
$$

where $\left[\begin{array}{lll}x_{l+1}^{\prime} & \lambda_{l+1}^{\prime}\end{array}\right]^{\mathrm{T}}$ is prediction value, which is an approximate solution. $h$ is the step size of the prediction.
3.3.2. The Corrector Step. In the corrector step, the prediction value of $\left[\begin{array}{ll}x_{l+1}^{\prime} & \lambda_{l+1}^{\prime}\end{array}\right]^{\mathrm{T}}$ is substituted into (19), and its iteration form is reformulated as

$$
\left[\begin{array}{cc}
f_{x}^{\prime} & f_{\lambda}^{\prime} \\
0 & 1
\end{array}\right]\left[\begin{array}{c}
\Delta x \\
\Delta \lambda
\end{array}\right]=-\left[\begin{array}{c}
f(x, \lambda) \\
0
\end{array}\right] .
$$

The iteration form is now reformulated as

$$
\left[\begin{array}{cc}
f_{x}^{\prime} & f_{\lambda}^{\prime} \\
e_{K} & 0
\end{array}\right]\left[\begin{array}{c}
\Delta x \\
\Delta \lambda
\end{array}\right]=-\left[\begin{array}{c}
f(x, \lambda) \\
0
\end{array}\right] .
$$

\section{Case Studies and Validations}

Two cases are considered and compared: (1) the system with existing AC transmission line and (2) the system with a new $\mathrm{dc}$ transmission line based on VSC-HVDC.

The system parameters of the four different control modes and the VSC converters adopted in the case studies are prespecified as listed in Table 1 . The initial DC variable parameters of VSC-HVDC system are shown in Table 2. In Table 2, the $N_{\text {bus }}$ identifies bus number of VSC-HVDC link connected to AC systems. The $P_{\mathrm{L}}$ and $\mathrm{Q}_{\mathrm{L}}$ are the load power of the bus VSC connected to. The $R_{\mathrm{d}}$ is the resistance of DC network. $R, X_{l}, P_{\mathrm{L}}$, and $Q_{\mathrm{L}}$ are given parameters. $P_{\mathrm{s}}$ and $Q_{\mathrm{s}}$ are calculated by power flow calculation of the original AC system, which is equal to the branch power of the original AC system.

4.1. Modified IEEE 14-Bus Text System. First, the proposed method has been applied to the modified IEEE 14-bus system shown in Figure 2. The AC line parameters of the system are the same as the IEEE 14-bus system. The difference is that a two-terminal VSC-HVDC transmission line is placed at bus 13 and bus 14 to replace the AC transmission line 13-14; that is, the $\mathrm{VSC}_{1}$ and $\mathrm{VSC}_{2}$ are connected to $\mathrm{AC}$ line of bus 13 and bus 14 , respectively.

This paper chooses the commutation bus of the buses 9 , 12,13 , and 14 as the research objects. According to the different 


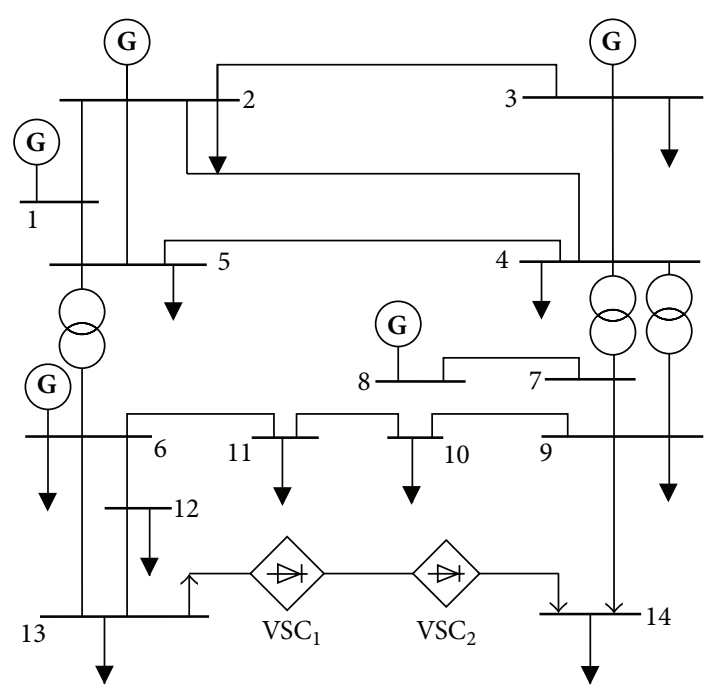

FIGURE 2: The modified IEEE 14-bus system with VSC-HVDC.

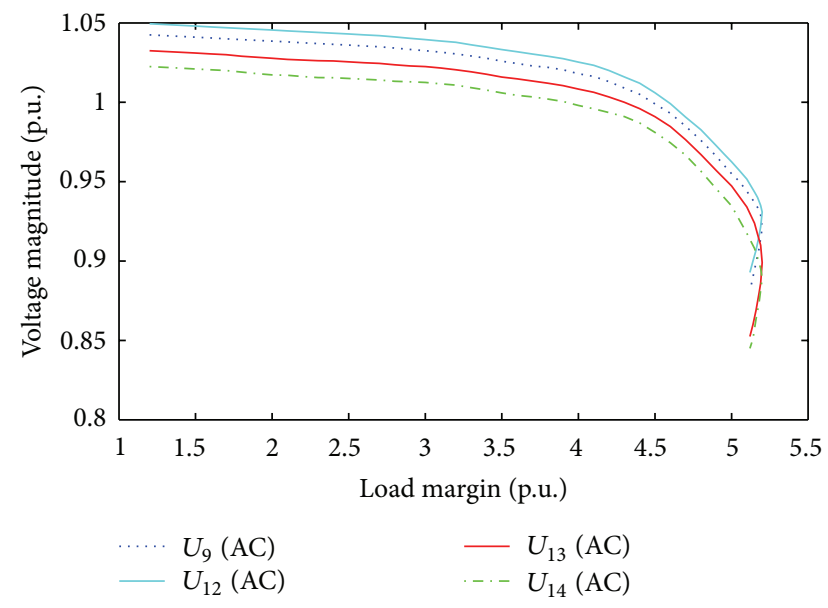

Figure 3: PV curves for IEEE-14 bus system.

control modes of VSC-HVDC showed in Table 1, the detailed analysis of the voltage stability bifurcation for the system can be divided into three cases.

4.1.1. The Operation Mode of " 1 ". Figure 3 shows the P-V curves and load margins of partial buses (buses 9, 12, 13, and 14) of the original pure IEEE-14 system ("AC" for short). Figure 4 shows the P-V curves and load margins of partial buses (buses 9, 12, 13, and 14) of the modified IEEE-14 system ("AC/DC" for short), in which the AC/DC system operates under the control mode " 1 " in Table 1 as the load increases. And Table 3 shows the power flow data of the VSC-HVDC operating in mode " 1 " at initial state and the maximum load state of the AC/DC system. Here, the maximum load state is corresponding to the saddle node bifurcation point of the system.

In Figure 3, when $\lambda_{\mathrm{AC}}=5.2120$ p.u., the saddle node bifurcation point is acquired, and the system is in maximum loading state. In Table 3, the "AC bus" of the lower half part
TABLE 3: Power flow data at initial and maximum load states for mode "1."

\begin{tabular}{lcccccc}
\hline Variable & $U_{\mathrm{d}}$ & $I_{\mathrm{d}}$ & $\delta$ & $M$ & $P_{\mathrm{d}}$ & $\mathrm{Q}_{\mathrm{d}}$ \\
\hline VSC $_{1}$ & 2.0000 & 0.4551 & 0.1370 & 0.8108 & 0.9153 & 0.1220 \\
parameters & 2.0000 & 0.4584 & 0.1947 & 0.6840 & 0.9240 & 0.1220 \\
VSC $_{2}$ & 1.9863 & -0.4551 & -0.1292 & 0.9387 & -0.8993 & 0.1734 \\
parameters & 1.9862 & -0.4584 & -0.3065 & 0.5505 & -0.8993 & 0.1734 \\
\hline Variable & $\mathrm{Q}_{\mathrm{s} 1}$ & $\mathrm{Q}_{\mathrm{s} 2}$ & $\mathrm{Q}_{\mathrm{s} 3}$ & $\mathrm{Q}_{\mathrm{s} 6}$ & $\mathrm{Q}_{\mathrm{s} 8}$ & - \\
\hline AC bus & -0.6999 & 0.1404 & 0.2347 & 0.0010 & 0.1045 & - \\
parameters & -0.0438 & 7.6425 & 1.5550 & 0.0014 & 0.5365 & - \\
\hline
\end{tabular}

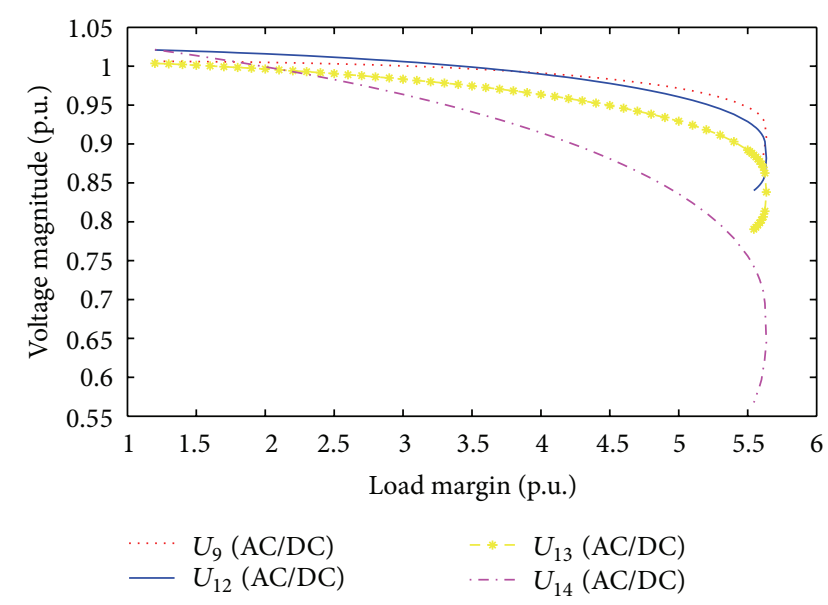

FIGURE 4: PV curves for modified IEEE-14 bus system in operating mode "1."

includes the four PV buses (bus 2, bus 3, bus 6, and bus 8 ) and a slack bus (bus 1) of the modified IEEE-14 test system. The upper row of the twin-row is the initial state data, and the lower row of the twin-row is the maximum load state (corresponding with the $\lambda_{\mathrm{AC} / \mathrm{DC}}=5.6358$ p.u. in Figure 4) data of power flow.

It can be seen in Figure 4 and Table 3, in operation mode "1," that the voltage magnitude decreases as the load increases, and the bus 14 (AC/DC) has the weakest voltage profile; so, it is the critical voltage bus needing reactive power support. When the load margin at $\lambda_{\mathrm{AC} / \mathrm{DC}}=5.6358$ p.u., the modified AC/DC systems present a collapse or saddle node bifurcation point, where the system Jacobian matrix becomes singular. And now the voltage drop of bus 14 (AC/DC) is the most obvious: $U_{14}=0.6451<U_{13}=0.8381<U_{12}=0.8816<$ $U_{9}=0.9083$ (the parameters are all the AC/DC systems).

4.1.2. The Operation Modes of "2" and "3". Figures 5 and 6 show the P-V curves and load margins of partial buses (buses $9,12,13$, and 14) of the AC/DC system under the control mode of " 2 " and " 3 ".

As shown in Figures 5 and 6, in operating mode "2" and mode " 3 ," the voltage magnitudes of bus 14 (AC/DC) and bus 13 (AC/DC) remain almost constant as the load increases, respectively. This is because the $\mathrm{VSC}_{2}$ in mode " 2 " and $\mathrm{VSC}_{1}$ in mode " 3 " both are in constant AC voltage control mode. 


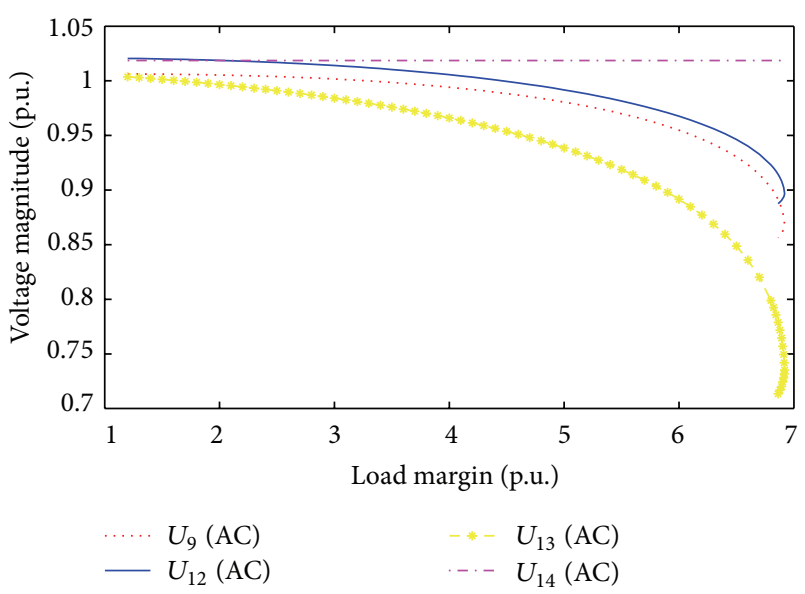

FIGURE 5: PV curves for modified IEEE-14 bus system in operating mode "2."

Besides, the load margins obtained in mode " 2 " $\left(\lambda_{\mathrm{AC} / \mathrm{DC}}=\right.$ 6.9192 p.u. $)$ and mode " 3 " $\left(\lambda_{\mathrm{AC} / \mathrm{DC}}=5.8980\right.$ p.u. $)$ are bigger than those in mode "1," which demonstrated that the VSCHVDC system supplies voltage support to the AC bus voltage, thanks to the benefits of the fast and independent reactive power output of VSC-HVDC.

4.1.3. The Operation Mode of " 4 ". Figure 7 shows the P-V curves and load margins of partial buses (buses 9, 12, 13, and 14) of the AC/DC system under the control mode of " 4 " in Table 1 with the load varies.

As shown in Figure 7, the voltage magnitude of bus 13 $(\mathrm{AC} / \mathrm{DC})$ and bus $14(\mathrm{AC} / \mathrm{DC})$ remains almost constant as the load increases. This because to the control modes of $\mathrm{VSC}_{1}$ and $\mathrm{VSC}_{2}$ are constant $\mathrm{AC}$ voltage. The load margin for this operation mode is $\lambda_{\mathrm{AC} / \mathrm{DC}}=7.7192$ p.u., which is bigger than those in other modes. Therefore, in the case of the VSCHVDC operation in mode "4," the AC/DC system has better voltage stabilization. But as has been pointed out in [27], when the AC/DC system is disturbed (such as kinds of faults), in order to maintain AC bus voltage, the VSC converter in mode "4" has to provide large amount of reactive power to the $\mathrm{AC} / \mathrm{DC}$ system. Consequently, the overload degree of VSC converter is more severe under this operation mode than overload degree of VSC converter under other control modes.

By contrasting the four control modes of VSC converters, the results show that the requirements of essential reactive power for AC system can be supplied by VSC-HVDC system, and the certain voltage support capability to AC bus by VSCHVDC link is validated. But it should be pointed out that the appropriate control pattern is the basis to exploit the reactive power compensation property of the VSC-HVDC system.

4.2. Modified IEEE 118-Bus Text System. The modified IEEE 118-bus system is analyzed in this section [28]. The relevant part of the network is shown in Figure 8, which shows the locations of the VSC-HVDC link. The VSC-HVDC replaced an existing $\mathrm{AC}$ transmission line (75-118), as shown in

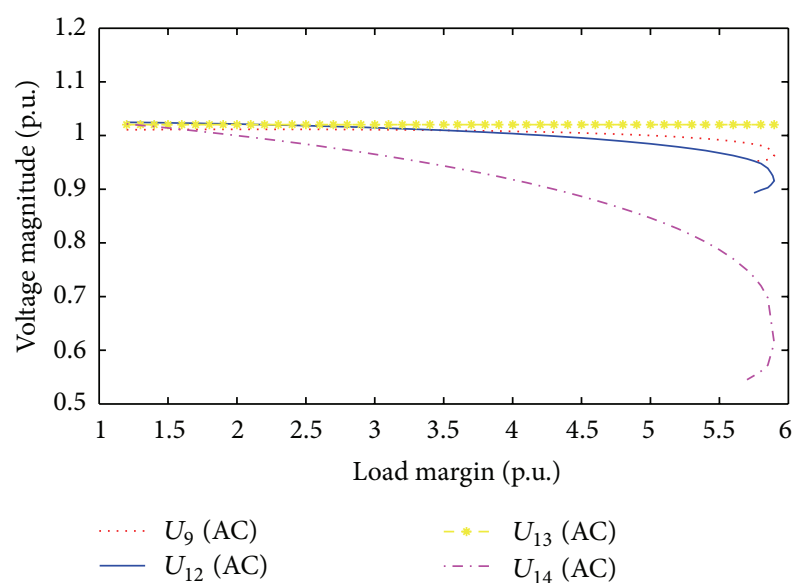

FIGURE 6: PV curves for modified IEEE-14 bus system in operating mode "3."

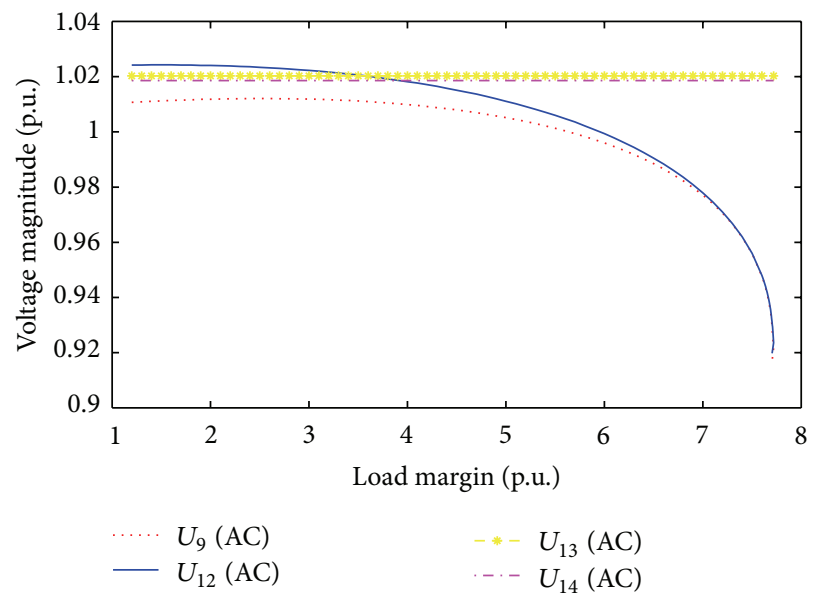

FIGURE 7: PV curves for modified IEEE-14 bus system in operating mode " 4 ."

TABle 4: Performance comparison of the modified IEEE-118 test system for four different operating modes.

\begin{tabular}{lcccc}
\hline The two cases & $\begin{array}{c}\text { Operation } \\
\text { modes }\end{array}$ & $\begin{array}{c}\text { Load margin } \\
\lambda \text { (p.u.) }\end{array}$ & $\begin{array}{c}\text { Iteration } \\
\text { numbers }\end{array}$ & $\begin{array}{c}\text { CPU time } \\
\text { in seconds }\end{array}$ \\
\hline AC/DC system & 1 & 4.6188 & 15 & 29.7642 \\
AC/DC system & 2 & 4.8750 & 15 & 32.0300 \\
AC/DC system & 3 & 4.8625 & 15 & 31.2754 \\
AC/DC system & 4 & 6.2750 & 15 & 76.4324 \\
\hline
\end{tabular}

Figure 8 , and the $\mathrm{VSC}_{1}$ and $\mathrm{VSC}_{2}$ are connected to $\mathrm{AC}$ line of bus 75 and bus 118, respectively.

The performance comparison of the modified IEEE-118 test system for four different operating modes is shown in Table 4. In Table 4, the CPU time for operation mode of " 4 " is longer than other operation modes. The reason is that the operation mode of " 4 " is in constant AC voltage control mode. As the load increases, the VSC-HVDC system supplies voltage support to the AC bus voltage, and as a result, the load margin of the AC/DC system in mode "4" is bigger 


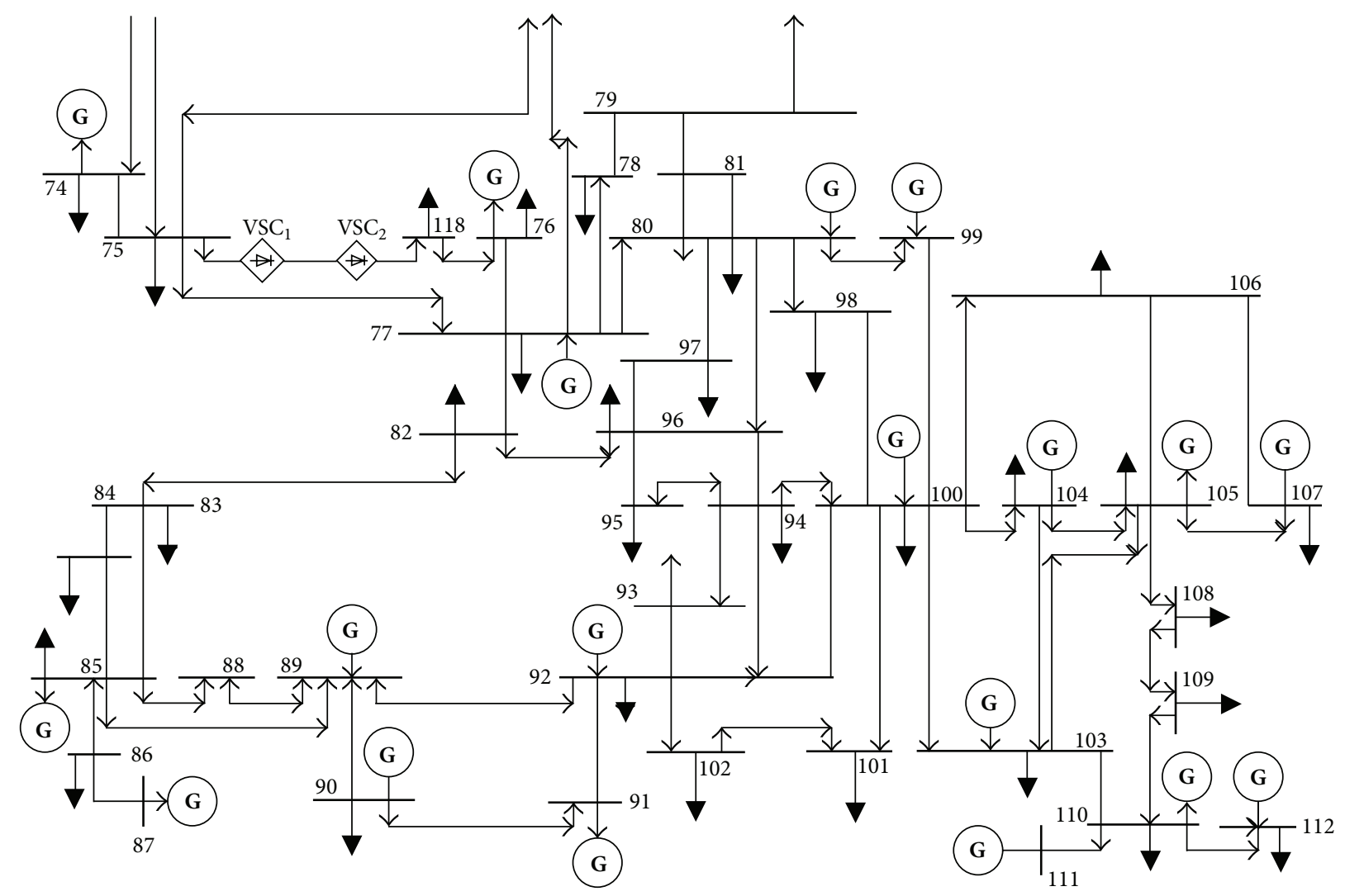

FIGURE 8: Relevant part of the modified IEEE 118-bus system withVSC-HVDC.

than other operation modes, and the calculation program for the load margin of the mode " 4 " needs more iteration; so, the CPU time is longer. Table 4 shows that the model and algorithm presented in this paper have certain flexibility with the increase of the network scale. However, it is to be remarked that the CPU time is long. The reason is that with the embedded VSC-HVDC transmission line, the types and the number of the system variables have greatly increased, that is, $P_{\mathrm{c} i}, Q_{\mathrm{c} i}, U_{\mathrm{d} i}, I_{\mathrm{d} i}, \delta_{i}, M_{i}, U_{\mathrm{c} i}, \theta_{\mathrm{c} i}$, and so forth, and the dimensions of the system equations and the Jacobian matrix of the AC/DC system have a higher order than pure AC systems.

\section{Conclusions}

In this paper, a new method has been developed to analyze voltage stability for AC/DC systems with VSC-HVDC. The impacts of load variations and different VSC-HVDC control patterns on P-V curves and saddle node bifurcation point of the system were numerically analyzed. The simulation results indicate that the constant AC voltage control of VSC converter is superior to other control modes in voltage stability and also show that VSC-HVDC significantly improved the stability of the system compared to a pure AC line. At last, the importance of suitable control mode for the operating of VSC-HVDC was discussed, and some numerical examples have been included to demonstrate the validity of the obtained results.

\section{Acknowledgments}

This work is supported in part by the National Natural Science Foundation of China (Grant nos. 61104045, 51277052, 51107032, and 51077125) and in part by the Fundamental Research Funds for the Central Universities of China (Grant no. 2012B03514).

\section{References}

[1] S. Kouro, M. Malinowski, K. Gopakumar et al., "Recent advances and industrial applications of multilevel converters," IEEE Transactions on Industrial Electronics, vol. 57, no. 8, pp. 2553-2580, 2010.

[2] N. Flourentzou, V. G. Agelidis, and G. D. Demetriades, "VSCbased HVDC power transmission systems: an overview," IEEE Transactions on Power Electronics, vol. 24, no. 3, pp. 592-602, 2009.

[3] Z. Huang, B. T. Ooi, L. A. Dessaint, and F. D. Galiana, "Exploiting voltage support of voltage-source HVDC," IEE Proceedings: Generation, Transmission and Distribution, vol. 150, no. 2, pp. 252-256, 2003.

[4] L. Zhang, L. Harnefors, and H. P. Nee, "Interconnection of two very weak AC systems by VSC-HVDC links using powersynchronization control," IEEE Transactions on Power Systems, vol. 26, no. 1, pp. 344-355, 2011.

[5] M. P. Bahrman and B. K. Johnson, "The ABCs of HVDC transmission technologies," IEEE Power and Energy Magazine, vol. 5, no. 2, pp. 32-44, 2007. 
[6] L. Zhang, H. P. Nee, and L. Harnefors, "Analysis of stability limitations of a VSC-HVDC link using power-synchronization control," IEEE Transactions on Power Systems, vol. 26, no. 3, pp. 1326-1337, 2011.

[7] Y. Jiang-Häfner, M. Hyttinen, and B. Pääjärvi, "On the short circuit current contribution of HVDC light," in Proceedings of IEEE PES Transmission and Distribution Conference and Exhibition, October 2002.

[8] F. L. Shun, M. Reza, K. Srivastava, S. Cole, D. van Hertem, and R. Belmans, "Influence of VSC HVDC on transient stability: case study of the Belgian grid," in Proceedings of the IEEE Power and Energy Society General Meeting (PES '10), Minneapolis, Minn, USA, July 2010.

[9] H. F. Latorre and M. Ghandhari, "Improvement of power system stability by using a VSC-HVdc," International Journal of Electrical Power and Energy Systems, vol. 33, no. 2, pp. 332-339, 2011.

[10] F. A. R. Al Jowder and B. T. Ooi, "VSC-HVDC station with SSSC characteristics," IEEE Transactions on Power Electronics, vol. 19, no. 4, pp. 1053-1059, 2004.

[11] J. Zhang and G. Bao, "Voltage stability improvement for large wind farms connection based on VSC-HVDC," in Proceedings of the Asia-Pacific Power and Energy Engineering Conference (APPEEC '11), Wuhan, China, March 2011.

[12] H. Livani, J. Rouhi, and H. Karirni-Davijani, "Voltage stabilization in connection of wind farms to transmission network using VSC-HVDC," in Proceedings of the 43rd International Universities Power Engineering Conference (UPEC '08), Padova, Italy, September 2008.

[13] C. Guo and C. Zhao, "Supply of an entirely passive AC network through a double-infeed HVDC system," IEEE Transactions on Power Electronics, vol. 25, no. 11, pp. 2835-2841, 2010.

[14] H. F. Latorre, M. Ghandhari, and L. Söder, "Active and reactive power control of a VSC-HVdc," Electric Power Systems Research, vol. 78, no. 10, pp. 1756-1763, 2008.

[15] H. F. Latorre and M. Ghandhari, "Improvement of voltage stability by using VSC-HVdc," in Proceedings of IEEE Transmission and Distribution Asia and Pacific Conference, Seoul, South Korea, October 2009.

[16] Y. Gao, Z. Wang, and H. Ling, "Available transfer capability calculation with large offshore wind farms connected by VSC-HVDC," in Proceedings of IEEE Innovative Smart Grid Technologies-Asia Conference, Tianjin, China, May 2012.

[17] L. C. Azimoh, K. Folly, S. P. Chowdhury, S. Chowdhury, and A. Haddad, "Investigation of voltage and transient stability of HVAC network in hybrid with VSC-HVDC and HVDC link," in Proceedings of the 45th International Universities' Power Engineering Conference (UPEC '10), pp. 1-6, Wales, UK, AugustSeptember 2010.

[18] X. P. Zhang, "Multiterminal voltage-sourced converter-based HVDC models for power flow analysis," IEEE Transactions on Power Systems, vol. 19, no. 4, pp. 1877-1884, 2004.

[19] A. Pizano-Martinez, C. R. Fuerte-Esquivel, H. Ambriz-Pérez, and E. Acha, "Modeling of VSC-based HVDC systems for a Newton-Raphson OPF algorithm," IEEE Transactions on Power Systems, vol. 22, no. 4, pp. 1794-1803, 2007.

[20] C. Angeles-Camacho, O. L. Tortelli, E. Acha, and C. R. FuerteEsquivel, "Inclusion of a high voltage DC-voltage source converter model in a Newton-Raphson power flow algorithm," IEE Proceedings: Generation, Transmission and Distribution, vol. 150, no. 6, pp. 691-696, 2003.
[21] C. Liu, B. Zhang, Y. Hou, F. F. Wu, and Y. Liu, "An improved approach for AC-DC power flow calculation with multi-infeed DC systems," IEEE Transactions on Power Systems, vol. 26, no. 2, pp. 862-869, 2011.

[22] U. Arifoglu, "The power flow algorithm for balanced and unbalanced bipolar multiterminal ac-dc systems," Electric Power Systems Research, vol. 64, no. 3, pp. 239-246, 2003.

[23] X. Wang, Y. Song, and M. Irving, Modern Power Systems Analysis, Springer, Berlin, Germany, 2008.

[24] T. Smed, G. Andersson, G. B. Sheble, and L. L. Grigsby, "A new approach to AC/DC power flow," IEEE Transactions on Power Systems, vol. 6, no. 3, pp. 1238-1244, 1991.

[25] S. H. Li and H. D. Chiang, "Continuation power flow with nonlinear power injection variations: a piecewise linear approximation," IEEE Transactions on Power Systems, vol. 23, no. 4, pp. 1637-1643, 2008.

[26] V. Ajjarapu and C. Christy, "The continuation power flow: a tool for steady state voltage stability analysis," IEEE Transactions on Power Systems, vol. 7, no. 1, pp. 416-423, 1992.

[27] C. Zheng, X. X. Zhou, and R. M. Li, "Dynamic modeling and transient simulation for voltage source converter based HVDC," Power System Technology, vol. 29, no. 16, pp. 1-5, 2005.

[28] Power Systems Test Case Archive, "University of Washington," http://www.ee.washington.edu/research/pstca/. 


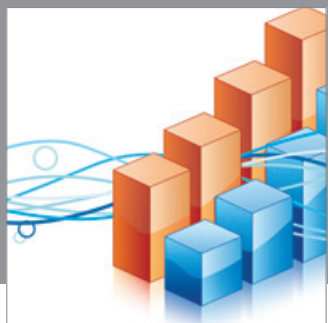

Advances in

Operations Research

mansans

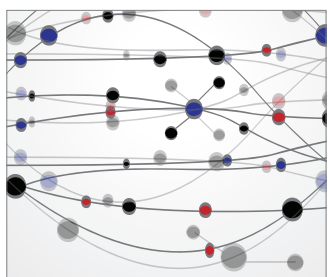

The Scientific World Journal
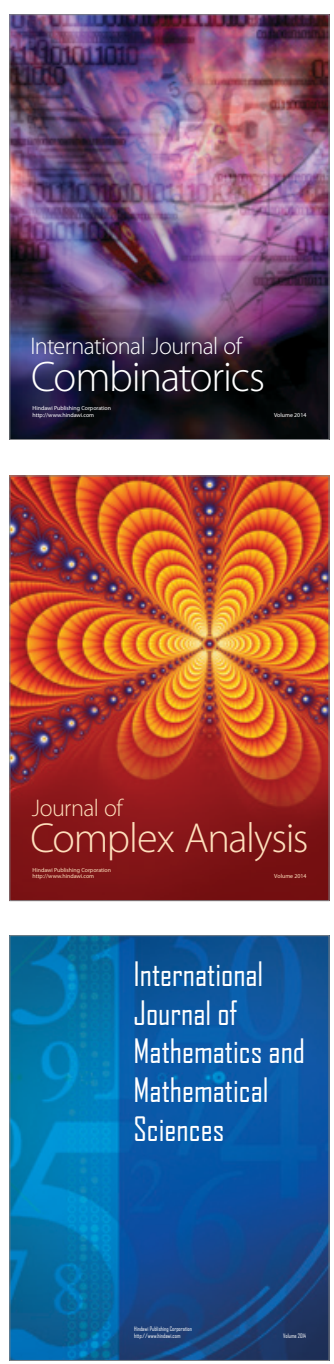
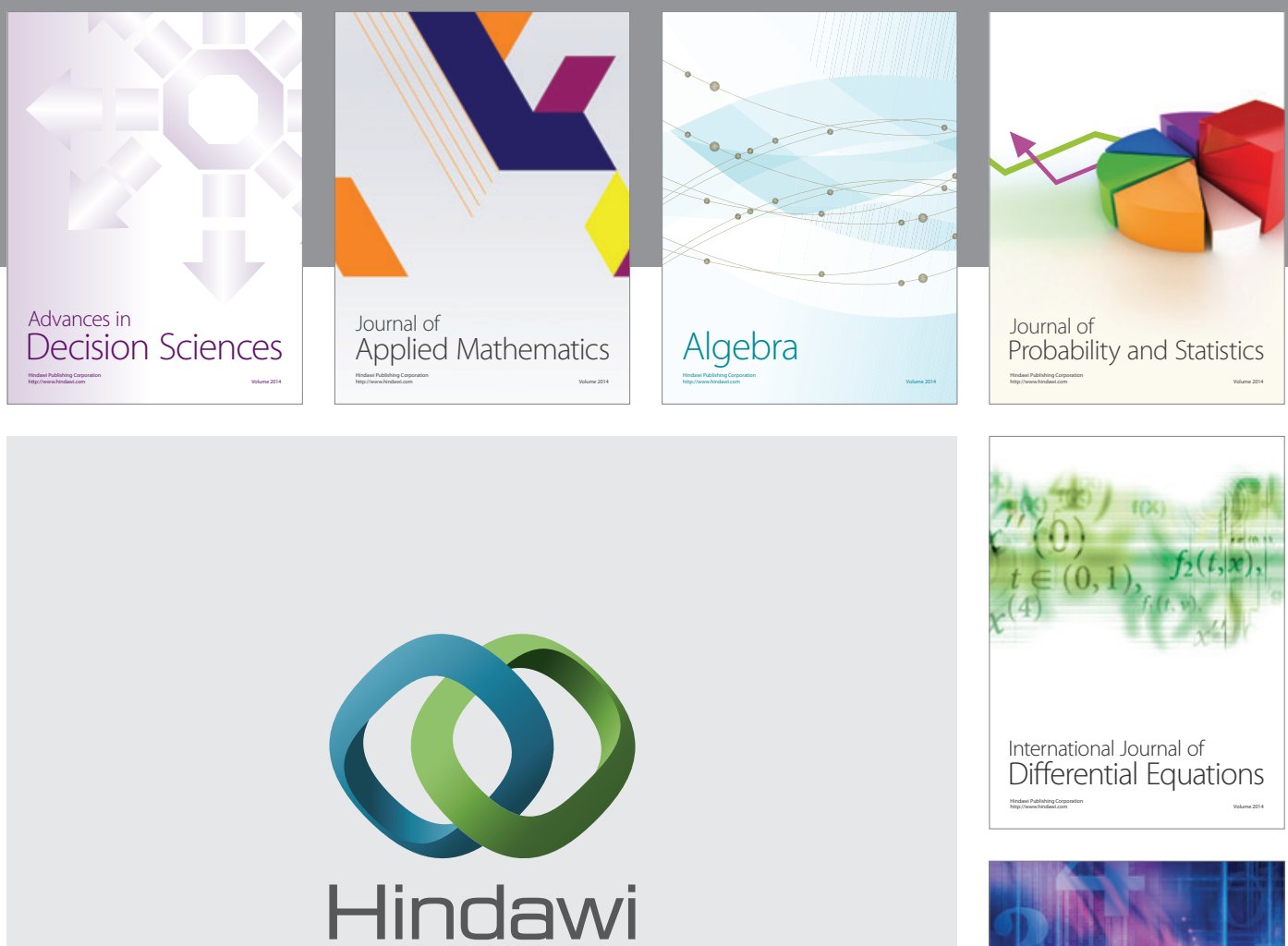

Submit your manuscripts at http://www.hindawi.com
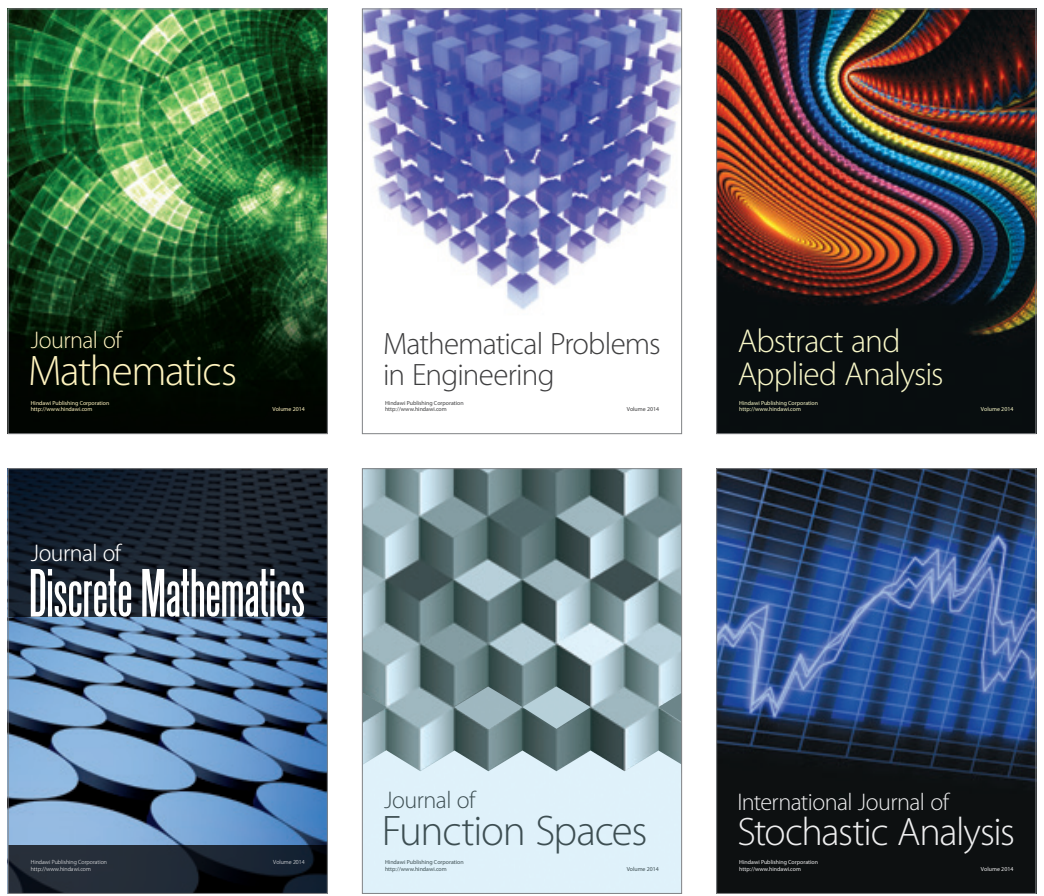

Journal of

Function Spaces

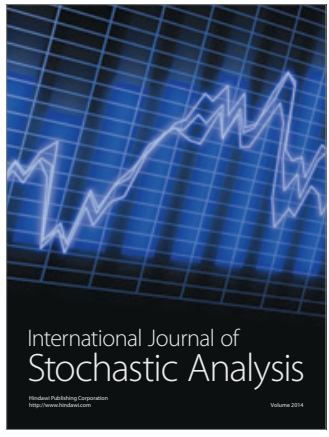

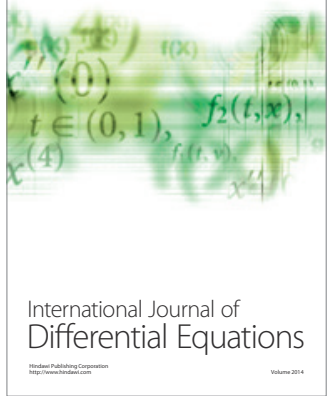
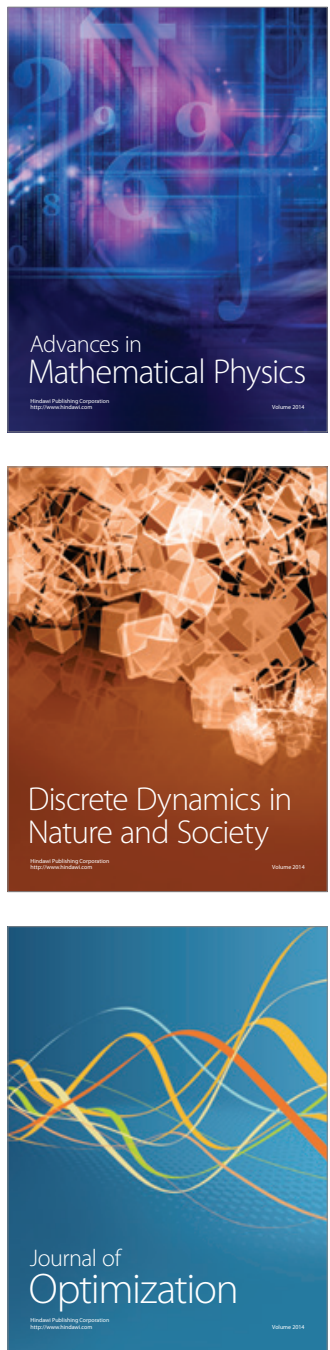